\title{
Qualijor - Sistema de Gestão da Produção Jornalística orientado para a qualidade editorial: Pesquisa Aplicada e de Desenvolvimento Experimental em Jornalismo ${ }^{1}$
}

\section{Josenildo Luiz Guerra}

\section{Resumo}

0 paper apresenta 0 Qualijor, um sistema de gestão da produção jornalística orientado para a qualidade editorial, que gera indicadores de desempenho para gestores e suas equipes. 0 Qualijor nasceu de preocupações teóricas aliadas à intenção da Pesquisa Aplicada e de Desenvolvimento Experimental (P\&D) tanto para medir a qualidade da atividade jornalística quanto para gerar inovação no processo produtivo, a fim de melhorar seus resultados. 0 esforço realizado pretendeu os seguintes resultados: 1) sugerir um modelo de gestão da produção jornalística com base em indicadores de avaliação de qualidade editorial; 2) sistematizar uma proposta metodológica de Pesquisa Aplicada e de Desenvolvimento Experimental em jornalismo.

\section{Palavras-Chave}

Jornalismo; Qualidade; Pesquisa Aplicada.
Josenildo Luiz Guerra | jl_guerra@uol.com.br Professor do curso de Jornalismo e do Programa de Pós-Graduação em Comunicação da Universidade Federal de Sergipe - UFS, Brasil. Doutor em Comunicação e Cultura Contemporâneas pela Universidade Federal da Bahia (UFBa).
0 texto irá apresentar 0 Qualijor, um software de gestão da produção jornalística orientado para a qualidade editorial, desenvolvido por uma equipe formada por integrantes da área de jornalismo e da engenharia da computação, liderada pelo autor do presente artigo. 0 objetivo é 1) caracterizar o Qualijor como um instrumento inovador para a gestão jornalística, por incorporar ao processo de produção indicadores de qualidade editorial que podem ser usados para a tomada de decisão e gestão do conhecimento organizacional; e 2) sistematizar a proposta de Pesquisa Aplicada e de Desenvolvimento Experimental construída ao longo de seu desenvolvimento ${ }^{1}$.

0 gerenciamento do fluxo de produção no Qualijor ${ }^{2}$ tem início com a inserção de uma proposta de notícia. Tal proposta será avaliada e poderá resultar em pauta, reportagem e texto final editado para veiculação. Em cada uma das etapas do ciclo de produção, é requisitada dos jornalistas a inserção de metadados ${ }^{3}$, os quais tipificam a informação com base em três aspectos: relevância, confiabilidade e pluralidade. 
A partir dos metadados inseridos, o sistema gerencia indicadores de desempenho, registrados e medidos ao longo de todo o processo de produção. As informações daí extraídas se tornam importantes ferramentas de gestão do conhecimento (Almeida, Freitas, Sousa, 2011) e apoio à decisão (Torres Jr., Moura, 2011; Façanha e Yu, 2011) para o trabalho jornalístico (Machado, $2006^{4}$ ). Através delas, é possível identificar os critérios aplicados pela equipe na avaliação técnica das matérias, o que permite revisar e avaliar o trabalho feito, usar os resultados para tomar decisões editoriais com base em dados (como decidir se matérias entram ou não na edição, e com que destaque) e oferecer transparência editorial para fins de accountability (Fendler, 2014; McQuail, 2003; Bertrand, 2002), entre outras possibilidades.

0 Qualijor foi concebido como solução para um problema prático: medir a qualidade de produtos jornalísticos e contribuir para a produção de produtos jornalísticos qualificados. A sua produção se deu em três etapas: adaptar a literatura da área de qualidade para a elaboração e sistematização dos parâmetros (requisitos e indicadores) de avaliação de qualidade em jornalismo; o desenvolvimento das metodologias de avaliação dos requisitos e indicadores; o desenvolvimento do software, que incorporou as metodologias, a fim de operacionalizar o processo de medição. A primeira etapa se constitui no esforço mais nitidamente de caráter aplicado, a segunda etapa já incluiu um esforço de desenvolvimento experimental que se consolidou na terceira etapa, com a criação do software. Certamente, 0 Qualijor tem ainda um caráter mais conceitual do que propriamente operacional, dado o seu estágio atual de maturação.

Todo esse esforço visou também a um problema teórico-metodológico: como sistematizar conceitualmente "a solução prática" dentro de

As definições de pesquisa básica, aplicada e desenvolvimento experimental usadas neste trabalho são do Manual Frascatti (2002). À frente, elas serão retomadas.

0 Qualijor (software) é registrado junto ao Instituto Nacional de Propriedade Intelectual (Inpi) sob o número BR 512015000113 2. 0 programa foi inicialmente batizado de Sistema de Gestão da Produção Jornalística (SGPJ), mas para fins de registro, foi denominado Qualijor. São seus autores: Josenildo Luiz Guerra, Débora Maria Coelho Nascimento (professora - Departamento de Computação - UFS), os estudantes de Engenharia de Computação Laerth de Jesus Bernardo, Elissandro Messias Santos e Ladyllsson Porto Silva Sobrinho; e as estudantes de Jornalismo Liliane do Nascimento Santos e Alanna Molina Vieira Lins.

Os metadados são "dados que descrevem uma informação ou objeto" em processamento no próprio sistema e que "permitem categorizar as informações e, assim, possibilitam que sejam efetuadas a organização semântica, a partir de determinados padrões, e também a formatação dos dados, ou seja, a parte sintática. A descrição e categorização do conteúdo favorecem a aplicação da técnica do tagging (etiquetagem), para classificar, contextualizar e recuperar a informação" (Barboza, 2008, p. 229). No caso do Qualijor, os indicadores de qualidade são os metadados inseridos no sistema. Essa e outras características do sistema o situam também no que Barboza (2008) irá propor como Paradigma do Jornalismo Digital em Base de Dados (JDBD).

Embora 0 autor se refira à intranet, os fundamentos que estão na base de seu raciocínio são perfeitamente aplicáveis ao sistema aqui descrito. 
uma proposta teórica e metodológica de caráter aplicado em jornalismo?

Por Pesquisa Aplicada em Jornalismo, e seu potencial desdobramento em Desenvolvimento Experimental, entende-se o conjunto de conhecimentos próprios sobre o jornalismo ou derivados de outras áreas, destinado a sistematizar um entendimento sobre a atividade, tendo em vista a sua execução. Tal formulação visa reunir e sistematizar conceitos, fundamentos e relações para dar conta de um modo de fazer. Dessa sistematização, extrai-se um problema de pesquisa, que é necessariamente um problema prático - uma limitação ou insuficiência do modo de fazer convencional - para o qual se busca uma solução inovadora ${ }^{5}$, capaz de gerar melhoria de desempenho. Essa solução inovadora pode requerer um instrumento igualmente inovador para sua implementação, do que resulta a necessidade de Desenvolvimento Experimental, isto é, construir algo capaz de implementar a inovação criada.

Para abordar os pontos aqui inicialmente esboçados, 0 seguinte roteiro será percorrido: 1) discutir o papel que a qualidade tem no cenário atual do jornalismo, haja vista ser ela o centro do problema prático que orienta a pesquisa; 2) apresentar a proposta de Pesquisa Aplicada em Jornalismo que resulte em Desenvolvimento Experimental; 3) apresentar o Qualijor e suas funcionalidades básicas.

\section{Qualidade em jornalismo}

0 cenário que caracteriza o jornalismo atualmente é desafiador quando consideradas várias perspectivas, desde o modelo de negócio até as incertezas sobre as fronteiras da própria atividade. Apesar disso, têm como efeito colateral positivo, ante a tantos outros que levam à tão propalada crise do setor, a abertura para projetos e ideias inovadores que buscam vislumbrar as oportunidades que o novo ambiente propicia. Uma dessas possibilidades é a que diz respeito à qualidade de produtos jornalísticos.

Um dos mais significativos trabalhos sobre 0 cenário atual da atividade, Post-Industrial Journalism: Adapting to the present (Anderson, Bell, Shirky, 2012), destaca que o "efeito das mudanças em curso no ecossistema jornalístico já tem levado à redução da qualidade das notícias nos Estados Unidos". Apesar disso, ou em função disso, quando abordam as transformações no trabalho do jornalista, os autores destacam que 0

Para este artigo, considera-se inovação nos termos do Manual de 0slo, conforme aponta Stal: inovação incremental, a introdução de qualquer tipo de melhoria em um produto, processo ou organização da produção dentro de uma empresa, sem alteração na estrutura industrial; inovação radical, a introdução de um novo produto, processo ou forma de organização da produção inteiramente nova (Stal, 2007, p. 32). Essa definição pode ser associada também à apresentada por Moreira e Queiroz (a partir de Knight, 1967) que classificam, com base no foco, quatro tipos de inovação: no produto ou serviço; no processo de produção, na estrutura organizacional e nas pessoas (Moreira \& Queiroz, 2007, p. 9-10). 
objetivo final do contínuo engajamento é produzir jornalismo de alta qualidade, temas e impactos significativos, para cujos objetivos e resultados, medidas serão rotineiras e públicas (Anderson, Bell, Shirky, 2012, p. 2 e 63 - grifo nosso).

A qualidade editorial é apontada como uma das condições necessárias ao jornalismo para superar a atual crise vivida pelo setor e manterse como uma instituição social de referência para as sociedades democráticas (Meyer, 2007). Judith Brito, por exemplo, ex-presidente da Associação Nacional de Jornais (ANJ), afirma que "vivemos um momento especial, histórico, em que paradigmas estão mudando. Não muda, no entanto, a necessidade das sociedades de terem informações, opiniões, e jornalismo de qualidade" (Brito, 2011 - grifo nosso).

0 problema é que, embora a discussão sobre a qualidade jornalística seja uma preocupação generalizada - todos de alguma forma a reivindicam ou a criticam -, há pelo menos duas grandes lacunas em se tratando de jornalismo. A primeira é a ainda incipiente e dispersa elaboração do tema no ambiente acadêmico destinado aos estudos em jornalismo $0^{6}$, capaz de estruturar conceitualmente uma abordagem que aglutine os vários esforços. A segunda, a ausência de métodos e critérios mínimos adequados para aferir a qualidade editorial de organizações jornalísticas em níveis aceitáveis de confiabilidade. Sem esses métodos e critérios, a discussão muitas vezes não avança e é relegada apenas a aspectos subjetivos, políticos ou ideológicos.

Desta situação resulta o desafio de desenvolver metodologias adequadas à empreitada e converter esse esforço em ferramentas que viabilizem sua operacionalização no ambiente de produção. Isso significa 1) definir o conceito de qualidade e de sua gestão aplicada ao jornalismo; 2) desenvolver metodologias de avaliação, baseadas em requisitos e indicadores de desempenho; e 3) o passo mais desafiador: ajustar processos e instrumentos de trabalho aos requisitos e indicadores, a fim de enquadrar a produção aos parâmetros considerados. Esses objetivos conduziram 0 desenvolvimento do Qualijor e, de alguma forma, estão presentes nele.

Todo esse movimento é altamente complexo, pois não há consensos sobre os requisitos, mesmo considerando parâmetros clássicos, como os de verdade, pluralidade, relevância; também falta consenso sobre os indicadores; falta consenso sobre métodos de avaliação; falta consenso inclusive sobre a necessidade de isso tudo existir. Há, portanto, além de todo o desafio técnicocientífico de elaborar um sistema de avaliação e 
produção orientadas para a qualidade, 0 desafio político de colocar o tema seriamente na agenda do setor e da sociedade.

Para os propósitos deste artigo, entretanto, não se irá entrar nem nos desafios relativos à validação dos parâmetros nem no desafio político de demonstrar sua necessidade. 0s parâmetros clássicos serão tomados como premissas, tendo o Paradigma Normativo da Media (Christians et al, 2009) $)^{7}$ e 0 Paradigma da Mediação como referência (Guerra, 2008) ${ }^{8}$. A partir deles, então, apresentam-se 0 Qualijor e a proposta de pesquisa aplicada aqui discutida.

Segundo a norma ABNT NBR IS0 9000:2005, qualidade é o "grau no qual um conjunto de características inerentes satisfaz a requisitos", sendo requisito a "necessidade ou expectativa [em relação a um produto ou serviço] que é expressa, geralmente, de forma implícita ou explícita”. Uma síntese possível do conceito de qualidade destaca a comparação entre características apresentadas pelos produtos e os requisitos: a) necessários para 0 seu funcionamento; e b) esperados pelos usuários. Quanto mais próximas as características estiverem dos requisitos, maior a qualidade.

No âmbito do Qualijor, são considerados três requisitos ${ }^{9}$ que atenderiam às expectativas da audiência e da sociedade: confiabilidade, 0 grau de confiança que a informação fornece em ser verdadeira; relevância, o grau de importância ou interesse que têm para a audiência e a sociedade; pluralidade, o grau de equilíbrio entre pontos de vista em situações de conflito. 0 Qualijor dá suporte, então, para a equipe de jornalistas identificar esses requisitos, medi-los através de indicadores de qualidade editorial e avaliar os níveis de desempenho alcançados.

\section{Pesquisa Aplicada e de Desenvolvimento Experimental em Jornalismo: uma proposta inicial}

As dificuldades que a área de jornalismo tem com a realização de pesquisa aplicada já foram assinaladas de modo contundente por pesquisadores brasileiros, sob diferentes ênfases (Meditsch, 2004; Machado, 2005; Franciscato, 2005). Meditsch, em uma análise histórica sobre os estudos em jornalismo no Brasil, aponta que, apesar de empresas do setor procurarem

0 aspecto essencial das teorias normativas que está na base dos parâmetros aqui desenvolvidos é o papel a ser desempenhado pelo jornalismo em sociedades democráticas.

No âmbito do paradigma da mediação, os parâmetros são decorrentes do papel mediador que o jornalismo realiza, seja na produção de conhecimento sobre os fatos e na sua consequente disponibilização para uma audiência que não pôde presenciar esses fatos diretamente, seja na mediação de conflitos que tenham lugar no espaço noticioso.

São tomados como premissa, sem necessidade de demonstração, por questão de espaço. 0 esforço para sua fundamentação pode ser conferido em Guerra (2008). 
na universidade colaboração para sanar seus

problemas, elas não têm encontrado "interlocutor interessado ou capacitado para essa parceria" (Meditsch, 2004, 99).

As empresas se deram conta de que a profissão já não pode se reproduzir 'na prática' como antigamente; a mutação cultural, social e tecnológica obriga a uma compreensão científica do que está ocorrendo. Nunca 0 jornalismo precisou tanto de PhDs, como observa Philip Meyer. Mas, a universidade não tem assumido 0 seu papel em nosso campo, porque não conseguimos ser uma 'ciência social aplicada' como deveríamos. (Meditsch, 2004, p, 99)

Machado, ao analisar um conjunto de investigações sobre o jornalismo, organiza os estudos em linhas de pesquisa. Na classificação apresentada, quando se refere à pesquisa aplicada, não a menciona no âmbito dos trabalhos produzidos no Brasil e a considera um "ramo incipiente" na produção internacional (Machado, 2005, p. 4 e 5). Uma das dificuldades apresentadas por ele para a consolidação das metodologias "adequadas ao campo", movimento que levaria ao fortalecimento da pesquisa aplicada, é o predomínio de abordagens motivadas por problemas teóricos e metodológicos de outras áreas. Nesse sentido, 0 autor propõe uma distinção entre "estudos em jornalismo", "realizados com metodologias oriundas em outros campos de conhecimento", e "teorias do jornalismo", "responsáveis pela experimentação metodológica dentro do campo", como primeiro passo para se dar um salto nas pesquisas da área rumo à investigação aplicada
(Machado, 2005, p. 8).

0 aspecto central dessa distinção não é nem a qualidade nem a importância das pesquisas em si, mas o foco. Na primeira, predominam problemas postos por motivação originada no âmbito das Ciências Sociais e Humanas. Na segunda, na mesma linha de Meditsch, prevaleceria o caráter de Ciência Social Aplicada, motivada pelo viés interno de questões próprias da atividade. Nessa direção, Machado destaca 0 necessário caráter multidisciplinar da pesquisa que permitiria "um conjunto diversificado e complementar de indagações" ser feito "sobre um mesmo objeto, com a vantagem de articular modelos metodológicos mais complexos, capazes de incorporar as preocupações das distintas disciplinas" (Machado, 2005, p. 11).

Franciscato (2005) também destaca a vinculação às ciências humanas como uma das dificuldades para a "formulação de um consistente aparato conceitual próprio que possa explicar a atividade".

Em vez disso, pesquisas em jornalismo têm sofrido uma tendência a conduzir suas discussões para 0 interior de disciplinas humanísticas fundadoras de quadros conceituais. Tal movimento redunda, pela própria natureza de rigor disciplinar da tradição, em uma exigência de o pesquisador em jornalismo dar conta dos problemas (epistemológicos inclusive) destas disciplinas, e tal enfrentamento Ihe faz tirar o foco principal sobre as questões conceituais específicas do jornalismo. (Franciscato, 2005, p. 2) 
Os desencontros nas formas de entender e de pesquisar o jornalismo são apontados também por Zelizer (2010), em termos que reforçam os dilemas da investigação em jornalismo assinalados por Meditsch, Machado e Franciscato. A autora identifica tensões entre as visões de jornalismo de três segmentos: profissionais, educadores e pesquisadores. Para ela, o lugar do jornalismo na academia constitui um projeto cheio de complicações, caracterizado por grupos de estudos isolados por área de conhecimento. "The result is that we have little consensus about the two key terms at the focus of our attention, agreeing only marginally about what journalism is and generating even less agreement about what the academy's relationship with it should be" (Zelizer, 2010, p. 29) ${ }^{10}$.

Na visão da autora, o jornalismo tem sido abordado em "pacotes", cada qual isolado dos outros. Tal compartimentalização age contra a clareza do que seja a atividade, analisando aspectos parciais em oposição a uma visão de conjunto. 0 resultado tem sido um terreno no qual o jornalismo está em guerra consigo mesmo (Zelizer, 2010, p. 35).

0s "desencontros" referidos por Meditsch, Machado, Franciscato e Zelizer podem ser vistos também sob a perspectiva das motivações da pesquisa. Para tanto, partimos da distinção entre três tipos de investigação:
A pesquisa básica consiste em trabalhos experimentais ou teóricos desenvolvidos principalmente com a finalidade de adquirir novos conhecimentos sobre os fundamentos de fenômenos e fatos observáveis, sem considerar uma aplicação ou uso particular. A pesquisa aplicada consiste igualmente em trabalhos originais empreendidos com o objetivo de adquirir novos conhecimentos. No entanto, ela é principalmente direcionada a um objetivo prático determinado. 0 desenvolvimento experimental consiste em trabalhos sistemáticos com base em conhecimentos existentes obtidos pela pesquisa ou experiência prática, para lançar a fabricação de novos materiais, produtos ou dispositivos, para estabelecer novos procedimentos, sistemas e serviços ou para melhorar os já existentes em P\&D. (Manual Frascati, 2002, p. 38 - grifo nosso)

Embora sem basear-se em um levantamento sustentado por dados, é possível sugerir que grande parte da pesquisa dedicada ao jornalismo é de natureza básica, pois o intuito é voltado a produzir uma compreensão do objeto e de suas múltiplas relações, sem necessariamente voltarse à solução de problemas práticos enfrentados pela atividade. Meditsch, Machado e Franciscato mostram, por exemplo, o predomínio dos estudos em jornalismo oriundos das Ciências Humanas, área na qual pesquisas de Desenvolvimento Experimental, as quais resultam da Pesquisa Aplicada, "têm pouco ou nenhum significado" (Manual Franscati, 2002, 101). Por isso, a ênfase desses autores para que o jornalismo se reconheça uma Ciência Social Aplicada.

10 "0 resultado é que temos pouco consenso sobre dois termos-chave que estão no foco de nossa atenção, concordando apenas marginalmente sobre o que é jornalismo e geralmente menos ainda sobre como deve ser sua relação com a academia" (Zelizer, 2010, p. 29 - tradução nossa). 
A pesquisa básica busca revisar e redefinir fronteiras e conceitos, oferecer um novo entendimento sobre o jornalismo, muitas vezes em oposição ao conhecimento até então consolidado, levantando "anomalias" que podem até gerar uma crise de paradigma (nos termos de Kuhn, 2013). Aí pode estar a origem dos desencontros entre a esfera acadêmica e a esfera profissional, uma vez que esta normalmente se edifica sobre os fundamentos da "ciência normal", isto é, o paradigma vigente. No âmbito da pesquisa básica, todas as possibilidades estão abertas para a investigação, seja para releituras, proposição de descobertas, críticas dos paradigmas postos, etc.

É o esforço da pesquisa aplicada que será capaz de produzir um arranjo propositivo que amarre teorias a procedimentos, e viceversa, uma vez que consiste em "trabalhos originais empreendidos com a finalidade de adquirir conhecimentos novos", mas é "dirigida principalmente a um objetivo ou um determinado propósito prático". Em função disso, desdobra-se, a partir da pesquisa básica, para "considerar os conhecimentos existentes e aprofundá-los com a finalidade de resolver problemas específicos". Em regra, "os resultados da pesquisa aplicada fundamentam-se, primeiro, em um único produto ou em um número limitado de produtos, operações, métodos ou sistemas" (Manual Frascati, 2002, p. 100).

A pesquisa aplicada "permite a formatação operacional de ideias", o que significa produzir uma sistematização conceitual que possa ser operacionalizada, através de métodos e procedimentos técnicos, na forma de mecanismos de gestão, de processos e de produtos que visem oferecer soluções ao “objetivo ou propósito prático" inicialmente estabelecido. A solução produzida, que é de natureza teórico-prática, no âmbito da pesquisa aplicada pode avançar para a etapa do desenvolvimento experimental, voltada à elaboração de novos produtos e processos que possam ser melhores em relação aos existentes.

A estrutura metodológica da proposta aqui sistematizada de Pesquisa Aplicada em Jornalismo requer considerar dois princípios elementares: o Princípio Finalidade e 0 Princípio Complementaridade. 0 Princípio Finalidade deve levar em conta os papéis que a instituição jornalística se propõe ou é solicitada a cumprir na sociedade, mediante acordos e convenções estabelecidos socialmente. Certamente, há nestes papéis uma dimensão ética e política fruto da institucionalização do jornalismo como atividade social, cujos contornos foram mais fortemente delineados nas sociedades democráticas modernas. 0 Princípio Complementaridade determina o respeito a eixos que, embora se refiram a questões de diferentes e específicas naturezas, juntamse em uma particular configuração para dar sentido e efetividade ao Princípio Finalidade, quando considerada a prática do jornalismo. 
0 Princípio Finalidade (PF) define um objetivo que se desdobra em um conjunto de responsabilidades socialmente assumidas ${ }^{11}$, em torno do qual a atividade jornalística se movimenta. Apresenta um objetivo institucional de referência, que pode ser detalhado em objetivos especializados, derivados e elaborados em diferentes graus de especialização. Entretanto, os objetivos especializados deverão sempre estar alinhados ao Princípio Finalidade.

A orientação dada pelo PF é essencial para a definição de parâmetros de desempenho em torno dos quais a atividade irá se realizar. Afinal, sem clareza do que se pretende atingir, não é possível fazer avaliações e nem qualquer julgamento de mérito do trabalho realizado. Por isso, o Princípio Finalidade expressa, nesse caso, uma razão de ser da instituição jornalística, que estabelece parâmetros de ação para toda e qualquer organização que se pretenda "jornalística"12.

Assim, de forma sintética, poderíamos expressar 0 Princípio Finalidade:

- A atividade jornalística se destina a produzir livremente notícias verdadeiras e plurais acerca de fatos reais do mundo, transmitidas por meio de algum suporte tecnológico, destinadas a compor uma agenda de questões que atenda às expectativas de relevância das audiências tanto em sua dimensão pública quanto em sua dimensão privada, restringindo-se em ambos os casos notícias sobre fatos que possam violar direitos e garantias individuais e coletivos, reconhecidos como valores humanos universais em sociedades democráticas.

Essa definição encontra guarida no âmbito das teorias normativas da mídia (Christians et al, 2009; Marinho, 2015, p. 36; Kovach, Rosenstiel, 2001) e do Paradigma da Mediação (Guerra, 2008), duas terminologias que caraterizam 0 modelo de jornalismo moderno que institui a base ética e técnica contemporânea da atividade em sociedades democráticas. Existe, certamente, a possibilidade de se propor outros princípios finalidades, os quais resultem em responsabilidades - e premissas - diferentes das reivindicadas e assumidas para a proposta aqui apresentada. Mas, do ponto de vista de uma pesquisa aplicada, o PF tem de ficar claro, pois ele será essencial para 0 trabalho de avaliação e de accountability das práticas existentes.

0 Princípio Finalidade deve obter fundamento em seis eixos em torno dos quais a atividade

11 No caso do jornalismo, McQuail (2003) aponta que essas responsabilidades são atribuídas, contratadas ou voluntárias, em função das relações socialmente estabelecidas, e que delas irão derivar os compromissos relativos a práticas de accountability.

12 Nesse sentido, o "Princípio Finalidade" está afeito à noção de jornalismo como ação racional conforme os fins e os valores, de acordo com Fonseca e Seibt (2015, p. 644) e Fonseca (2016), a partir da categoria de ação racional de Max Weber. 
jornalística estrutura a sua operação. É uma exigência do Princípio Complementaridade, que demanda um alinhamento de saberes entre esses eixos:

1) Teoria do jornalismo: 0 conjunto de obrigações e objetivos contidos no Princípio Finalidade deve ter respaldo teórico. Para esta pesquisa, por exemplo, tomamos como premissas os conceitos de verdade, relevância e pluralidade, conforme desenvolvidos por Guerra (2008), e dos compromissos básicos do jornalismo em sociedades democráticas (Gomes, 2004; Gentilli, 2005; Norris \& Odugbemi, 2008; Christians et $a l, 2009)$. A articulação entre 0 estabelecido no Princípio Finalidade e o eixo Teoria do Princípio Complementaridade é essencial para 0 caráter aplicado da compreensão do jornalismo como objeto da intervenção científica e tecnológica sobre ele. Em todos os outros eixos, com certeza, há fundamentos teóricos, mas aqui se considera a teoria voltada especificamente ao jornalismo (Machado, 2008). Isto é, qualquer solução proposta para um problema tem de ter um respaldo teórico no âmbito do jornalismo, o qual deverá, por sua vez, interagir com os saberes e desafios dos outros cinco eixos.

2) Técnica: conjunto de modos de fazer considerado eficaz para atingir os objetivos previstos no Princípio Finalidade. As técnicas, para obterem validade, precisam estar em conformidade com o quadro de referência teórica que sustenta os compromissos do Princípio Finalidade. As técnicas inovadoras precisam também ser objeto de avaliação teórica - a fim de certificar sua consistência - e, claro, sua adequação ao estabelecido no Princípio Finalidade. E precisam ser compatíveis com a ética, com os processos, com a tecnologia e demais eixos de competências. Por exemplo, uma nova técnica de apuração que fira normas éticas ou que não encontre viabilidade tecnológica terá dificuldades para ser incorporada à profissão.

3) Ética: no plano profissional, essas referências se tornam normas deontológicas (Cornu, 1998). A normatividade ética decorrente desse processo deve ser suportada tanto teórica (a ética enquanto disciplina da Filosofia) quanto socialmente (0 reconhecimento da validade da norma). Qualquer inovação técnica ou conceitual no jornalismo, por exemplo, deve ser confrontada com 0 referencial ético que norteia a atividade, para se analisar eventuais conflitos ou riscos não admissíveis.

\section{4) Processos ${ }^{13}$ : sequência organizada de} um conjunto de atividades que transforma a informação inicial interpretada da realidade ou oferecida pelas fontes no produto final notícia. Nesse fluxo, uma série de procedimentos técnicos de confirmação de veracidade, avaliação de 
relevância, avaliação ética, entre outras, é combinada com procedimentos operacionaisadministrativos (como a logística de realização das coberturas) que vão conformando o produto final. A busca pelo melhor processo jornalístico visa estruturar a melhor forma de execução da atividade, a fim de se obter os melhores resultados no âmbito de uma organização. A definição dos processos precisa estar, igualmente, respaldada pelos outros eixos.

\section{5) Suporte Tecnológico: conjunto de} equipamentos e de competências para operálos, bem como a rede de serviços necessária ao seu funcionamento, para viabilizar o processo jornalístico. No caso do Qualijor, a ênfase está no uso de sistemas de informação, "um conjunto organizado de pessoas, hardware, software, redes de comunicação e recursos de dados que coleta, transforma e dissemina informações em uma organização" (0’Brien, 2010, p. 6), o qual se insere no contexto do conceito de Jornalismo Digital em Base de Dados (Machado, 2006; Barboza, 2008). É impossível a prática jornalística sem a infraestrutura e os dispositivos tecnológicos de produção e disseminação de seus produtos. No caso específico do jornalismo, 0 uso mais sofisticado de softwares e sistemas de gestão editorial pode alavancar os recursos de gestão do conhecimento e emprego de dados para apoio à tomada de decisão editorial. Seguindo a regra geral do Princípio Complementaridade, a tecnologia precisa interagir com os demais eixos, para evitar conflitos de utilização.
6) Sustentabilidade: capacidade de uma organização tornar-se viável, mantendo suas atividades em caráter regular. A sustentabilidade pode ser pensada em três dimensões: ambiental, social e econômica. No caso específico da econômica, as estratégias são validadas - ou não - eticamente, por exemplo, pois a autonomia financeira é uma condição das mais importantes para proporcionar a independência editorial. Assim, os recursos previstos nos demais eixos precisam ser viáveis no plano da sustentabilidade.

\section{Princípio Complementaridade sinaliza para a} necessária articulação dos seis eixos entre si e com as determinações do Princípio Finalidade. Para que o firmado no Princípio Finalidade se materialize, é necessário um suporte teórico que o sustente, um conjunto de normas éticas que o valide socialmente, um conjunto de técnicas, processos e suporte tecnológico que 0 implemente, além de sustentabilidade, isto é, uma relação viável entre financiamento do negócio, custos de produção e perenidade.

Os eixos do Princípio Complementaridade não se confundem com linhas de investigação, como Machado (2005, p. 3-5) e Franciscato (2005, p. 5-7), por exemplo, sugerem como áreas de realização, promissoras ou potenciais para a pesquisa aplicada. Como princípio metodológico, o que os eixos determinam é a interdependência entre os saberes teóricos e práticos produzidos no âmbito de cada um. Essa interdependência é condição essencial para que os "pacotes", 
nos termos de Zelizer, superem o isolamento e dialoguem com as demais competências necessárias para se pensar a atividade. Qualquer intervenção em um dos eixos precisa ser relacionada imediatamente aos outros, a fim de não se perder a dimensão sistêmica do jornalismo como atividade social e profissional ${ }^{14}$.

A Pesquisa Aplicada busca, então, solucionar um problema, identificado a partir das diretrizes do Princípio Finalidade, cuja solução deve atravessar os seis eixos do Princípio Complementaridade, de forma alinhada e articulada. Tal solução, contudo, pode requerer instrumentalização para ser implementada. Isto é, pode exigir que métodos e materiais resultem em um constructo para proporcionar sua aplicação regular. Nesse momento, inicia-se a fase de Desenvolvimento Experimental, para que se construa algo capaz de viabilizar a solução proposta. Para tanto, são necessários vários testes destinados a aperfeiçoar o grau de aplicabilidade do instrumento, visando à sua incorporação ao ambiente de produção regular. Nesse processo, o constructo se constitui em um "fator experimental" (Rudio apud Franciscato, 2005, p. 10) a ser testado nas várias situações simuladas ou reais para as quais pretende ser uma solução.

Na sequência, irá se apresentar a solução que 0 Qualijor oferece ao problema da avaliação de qualidade de produtos jornalísticos e o próprio software como resultado de um processo de Desenvolvimento Experimental.

\section{Qualijor: descrição e aplicações}

0 problema prático que orientou a Pesquisa Aplicada - como medir e avaliar o desempenho de produtos jornalísticos em relação à sua qualidade editorial - teve como solução 0 desenvolvimento de um conjunto de metodologias que gerou três índices de qualidade editorial: Índice de Relevância Jornalística (IRJ), Índice de Confiabilidade Jornalística (ICJ) e Índice de Pluralidade Jornalística (IPJ). Nesse conjunto de índices e em suas respectivas metodologias repousa a resposta ao problema da Pesquisa Aplicada. Infelizmente, por questão de espaço, não é possível detalhar cada uma dessas metodologias.

Para se operacionalizá-las, foi avaliado que um software poderia agregar vários componentes importantes para otimizar os resultados da avaliação de qualidade alcançados. Com 0 software, além da avaliação em si, seria possível incorporar os indicadores e índices de qualidade a processos de tomada de decisão editorial e de gestão do conhecimento organizacional. 0 software foi, portanto, o constructo resultante do Desenvolvimento Experimental, a fim de operacionalizar a metodologia de avaliação de qualidade desenvolvida para responder ao problema posto no âmbito da Pesquisa Aplicada. 
A avaliação de qualidade sistematizada no Qualijor contemplou, então, o conjunto dos eixos do Princípio Complementaridade de modo articulado com o Princípio Finalidade considerado. 0 sistema e os requisitos nele embarcados têm uma fundamentação teórica, são respaldados por uma avaliação ética, são compatíveis com técnicas profissionais vigentes e sugerem técnicas inovadoras que podem ser incorporadas pela profissão; são compatíveis com processos existentes e sugerem incrementos possíveis de serem incorporados; a tecnologia disponível permite realizar as proposições feitas através do conceito do Qualijor e dos seus requisitos; 0 desenvolvimento do Qualijor e a incorporação dos requisitos de qualidade ao processo jornalístico exigem um investimento que pode ser compatível com a sustentabilidade das organizações, vindo inclusive a contribuir com ela, pelo valor agregado em qualidade que pode proporcionar.

\section{Qualijor é destinado à gestão do processo de} produção jornalística com base em indicadores de qualidade editorial. Através do software, é possível: controlar o fluxo do processo de produção, estruturado em cinco etapas: triagem, pauta, reportagem, composição e edição; registrar indicadores de relevância usados na avaliação das matérias, em cada etapa do processo; registrar indicadores para avaliar a confiabilidade das informações; registrar indicadores para avaliar a relevância das notícias; registrar indicadores de pontos de vista para avaliar a pluralidade da cobertura, entre outros recursos. Todas as funcionalidades anteriormente citadas geram indicadores e índices capazes de permitir a gestão da qualidade editorial em tempo real para 0 gestor de conteúdo ${ }^{15}$.

Em linhas gerais, os mecanismos básicos de funcionamento são os seguintes:

\section{1) Cadastro de Produções Jornalísticas: a}

produção jornalística é cadastrada, tem definida sua periodicidade, editorias e prazos por etapa de produção, entre outras informações; 0 sistema possibilita gerenciar várias produções simultaneamente, proporcionando visibilidade entre elas, quando da mesma organização, como instrumento de gestão do conhecimento.

\section{2) Configuração das Matrizes de Relatos,} Problemas e Relevância: cada matriz é configurada de acordo com a proposta da organização e com o perfil editorial do produto; não é necessário operar apenas com uma matriz, embora possa haver matrizes que se consolidem e sejam operadas por um grupo de produções jornalísticas; são através dessas matrizes que os metadados serão inseridos para gerar os índices de relevância, confiabilidade e pluralidade. 
Figura 1: Página inicial e menu para configuração de matrizes (em destaque)

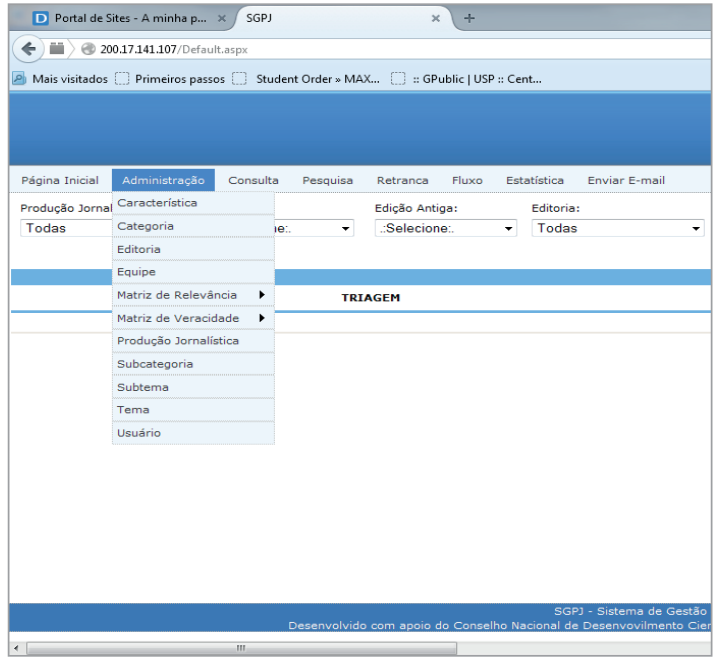

Obs: Onde se lê Matriz de Veracidade, leia-se Matriz de Relatos, termo atualmente usado pela equipe de pesquisa, que é usada para gerar dois índices: 0 de confiabilidade e 0 de pluralidade.

\section{3) Informação visual do fluxo da produção:}

cada etapa do processo tem uma coluna específica, identificada por sua respectiva cor, o que favorece a identificação e leitura das informações; na Figura 2, azul-claro é triagem; azul-escuro, pauta; verde, reportagem; vermelho, composição; amarelo, edição. À medida que a notícia evolui no processo, ela vai para a coluna correspondente. 0 s metadados da coluna anterior ficam registrados, para fins de documentação e gestão do conhecimento.

Figura 2: Controle de fluxo das matérias, da triagem (coluna azul-claro) à edição (coluna amarela)

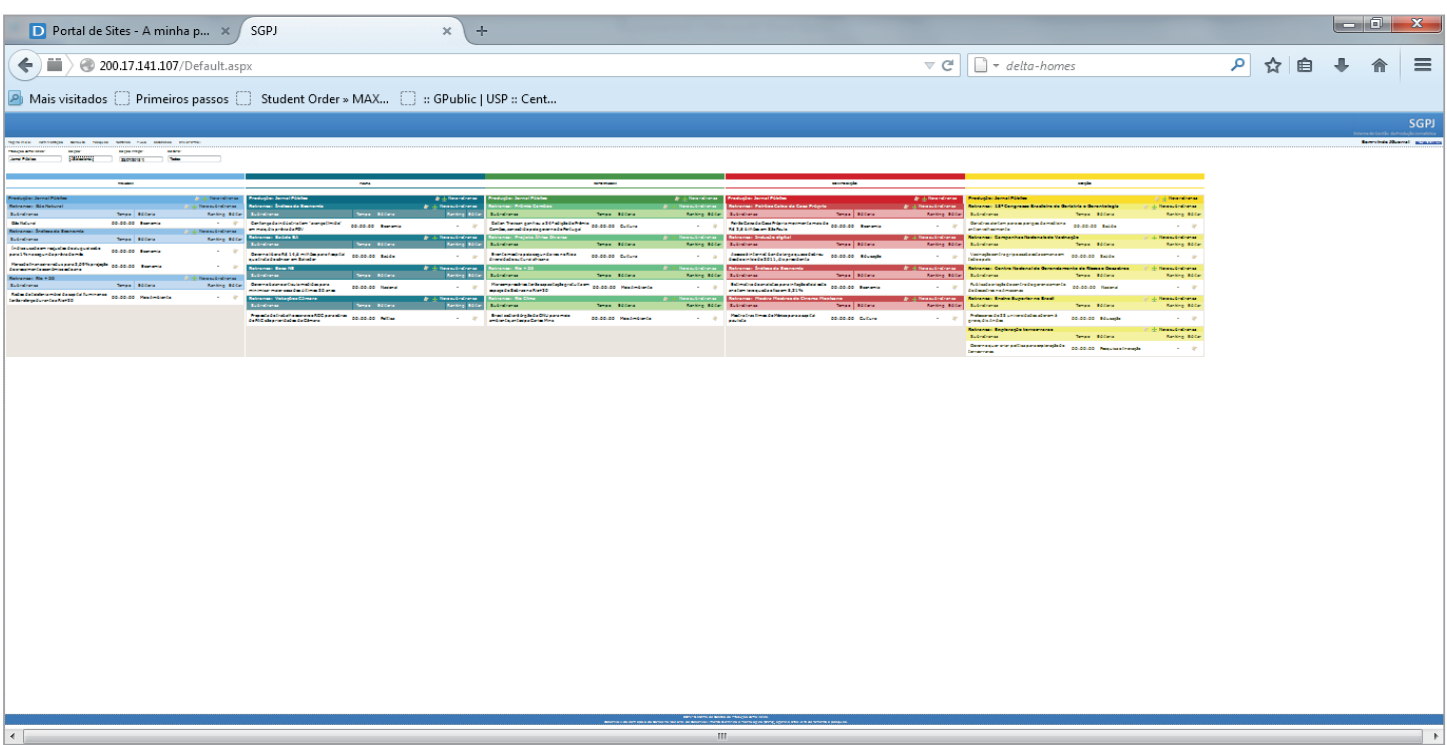


4) Cadastro de Retrancas e Sub-

retrancas: a inserção de matérias se dá por retranca e sub-retranca; a retranca é uma rubrica que identifica um assunto dentro do qual podem ser desdobradas várias matérias (sub-retrancas).
5) Inserção de relato (informação): cadastrada a retranca, é feita a inserção de relatos; cada relato configura uma unidade informativa da notícia; a montagem da matéria por relatos é necessária para a avaliação de confiabilidade e de pluralidade, cujos indicadores são atribuídos aos relatos.

Figura 3: Campo para inserir informações (relatos), unidades informativas que formam a notícia

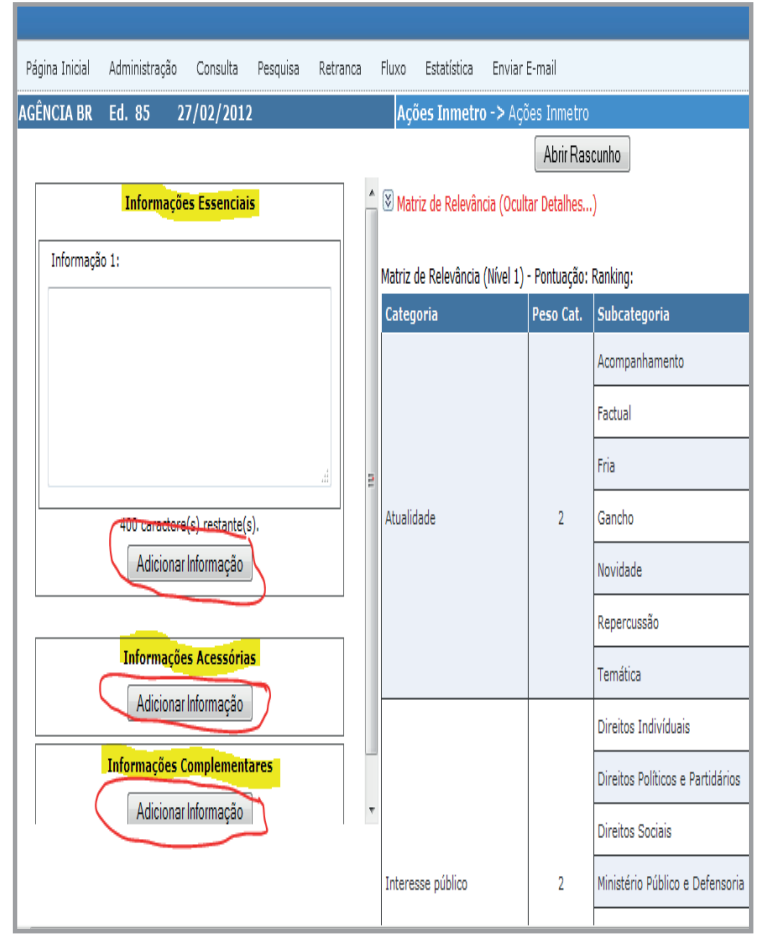

Obs.: A "informaç̧ão" que identifica o conteúdo da caixa é o relato.

\section{6) Cadastro e tipificação de fontes de}

informação: 0 sistema prevê 0 cadastro das fontes, assim como sua tipificação de acordo com categorias próprias, capaz de relacioná-las aos relatos; dessa forma, é possível identificar quais fontes produzem que tipos de relatos, o que é especialmente importante para a avaliação de pluralidade, por exemplo, em que se pode associar as fontes aos pontos de vista apresentados.

\section{7) Inserção de indicadores de qualidade}

editorial: atribuição dos indicadores de qualidade editorial à notícia e aos relatos; resulta na produção estruturada da notícia; esses registros serão recuperados para o cálculo dos índices de Relevância, de Pluralidade e de Confiabilidade. 
Figura 4: Exemplo de atribuição de relevância a partir de uma Matriz de Relevância e seu respectivo sistema de pontuação

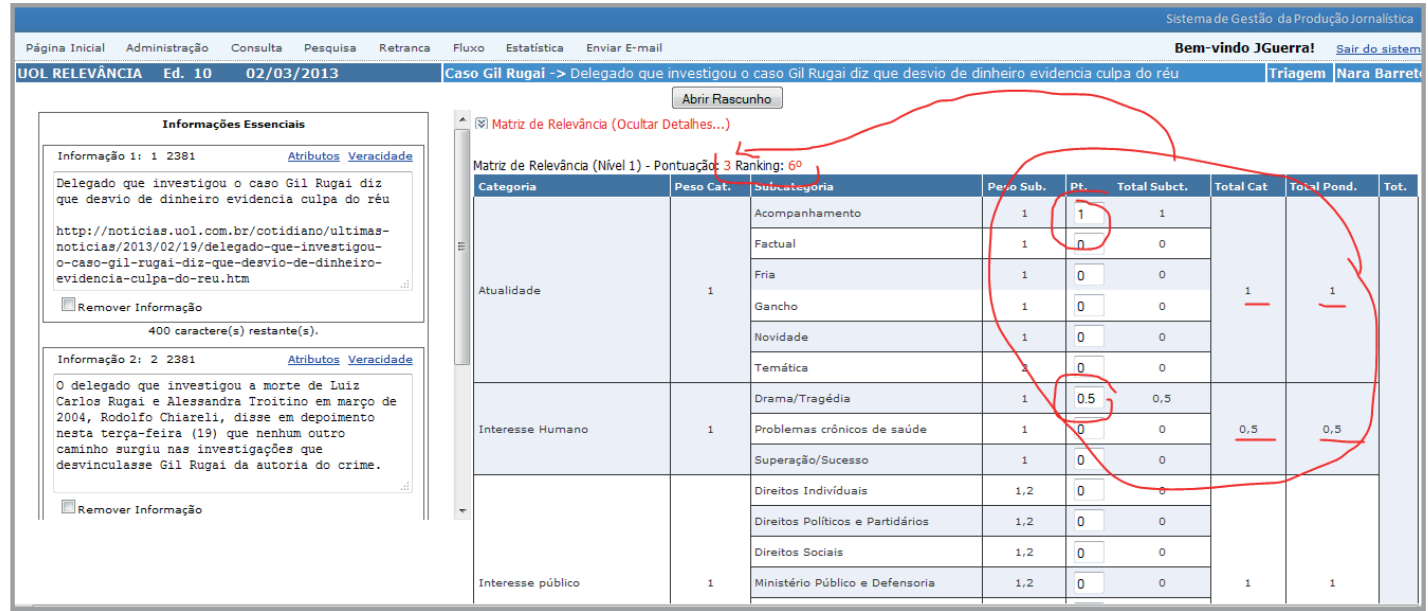

8) Sistema de ranking: 0 sistema gera um

ranking automático de relevância das notícias e de confiabilidade das informações.

\section{9) Sistema de consultas: 0 sistema}

disponibiliza consultas para gerar o quantitativo dos indicadores de qualidade para cada produção jornalística, a partir dos quais se gera um conhecimento sobre várias decisões editoriais que, normalmente, ficam implícitas; com 0 Qualijor, os parâmetros de relevância e de confiabilidade são informados pelos jornalistas, tornando-se um recurso de gestão do conhecimento organizacional e de apoio à tomada de decisão; 0 sistema permite vários tipos de filtros e cruzamentos.

Figura 5: Exemplo de consulta ao ranking de relevância

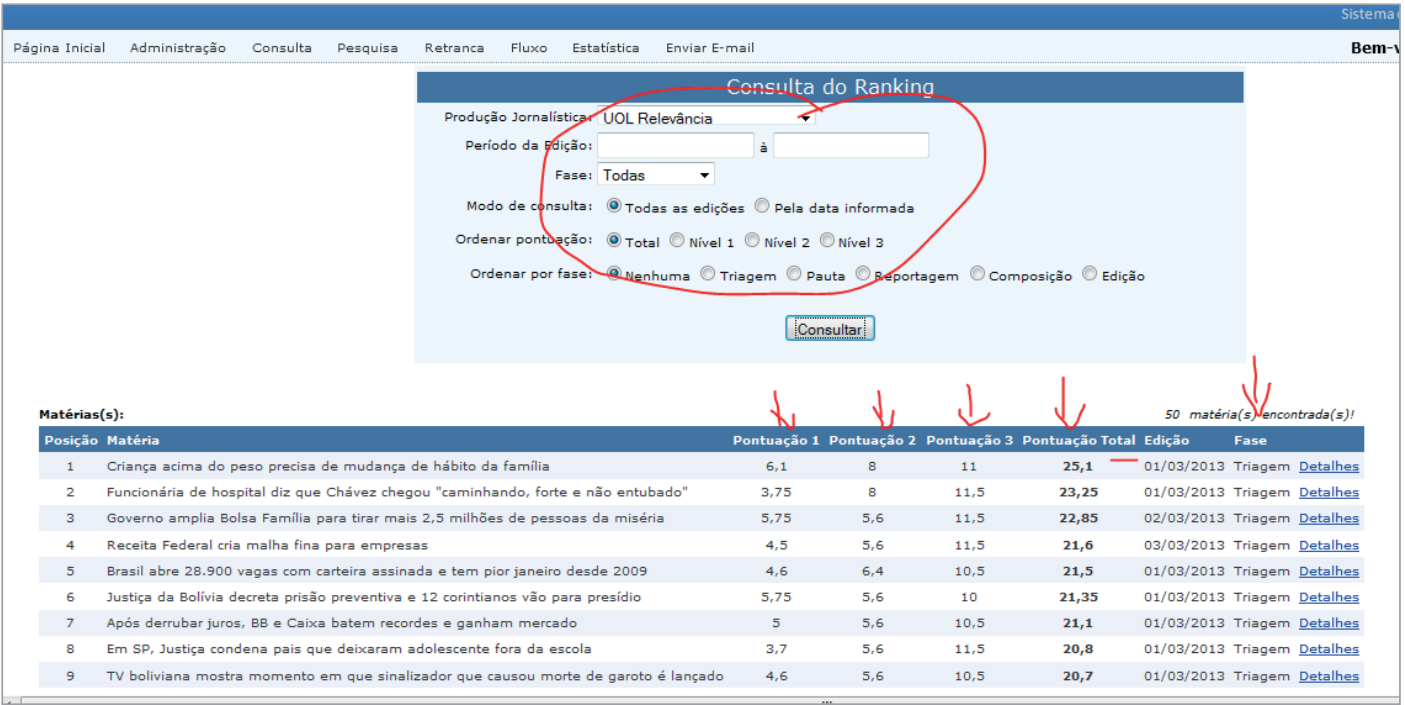


Figura 6: Página* de consultas, através da qual é possível selecionar produções jornalísticas e categorias, além de fazer vários tipos de filtros e cruzamentos

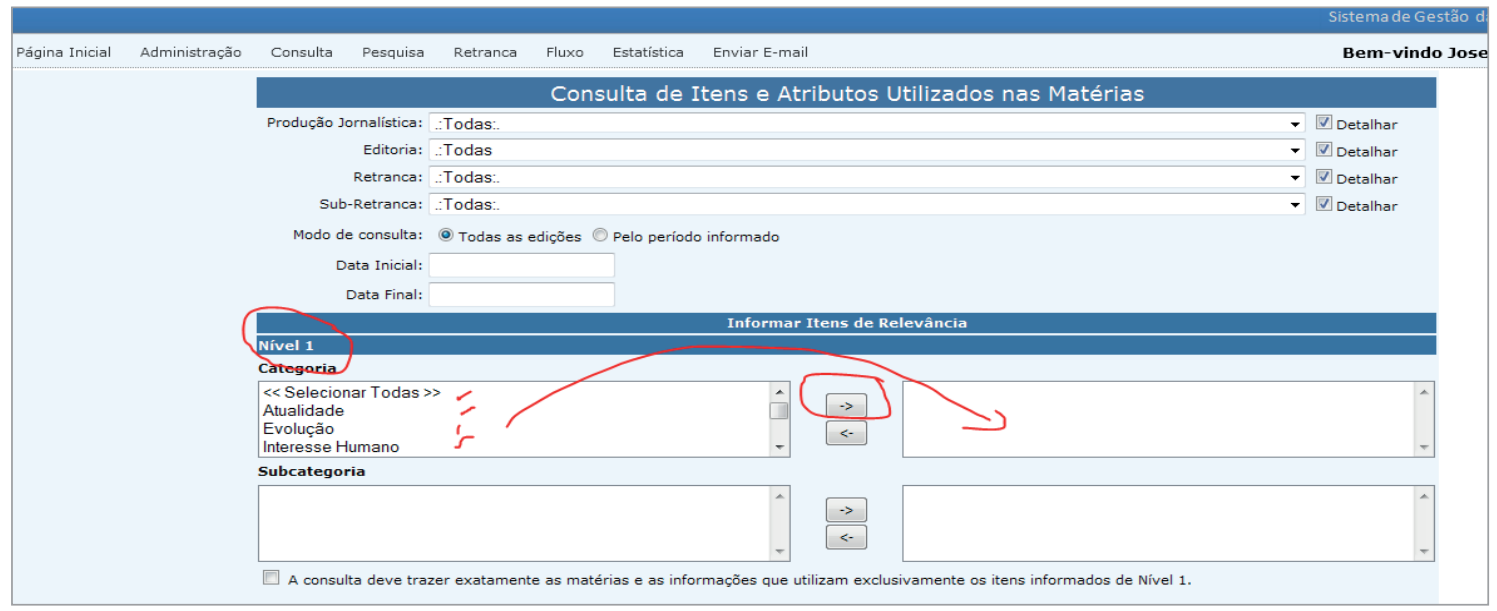

*Reprodução parcial da tela.

A seguir, alguns exemplos de dados gerados pelo sistema, aplicáveis à gestão da qualidade:

\subsection{Indicadores e Índices de Relevância Jornalística (IRJ)}

A partir da aplicação da Matriz de Relevância ${ }^{16}$ (um conjunto de valores-notícia, sistematizados em categorias, que pontua as matérias de acordo com a presença e a intensidade dos valores-notícia nela encontrados; quanto maior a pontuação, maior a relevância), é possível medir o grau de relevância das notícias. Por exemplo, na Figura 5 , pode-se constatar a relevância de notícias (identificadas pelo título) medidas a partir da aplicação da matriz. Se esse recurso é aplicado em uma edição, ajuda 0 editor a definir, baseado em critérios técnicos tornados explícitos, o destaque de cada notícia. Se o recurso é aplicado na fase de pauta, auxilia a selecionar quais propostas devem seguir adiante. No conjunto das notícias, é possível analisar se o material publicado está atingindo pontuações de alta, de média ou de baixa relevância.

Além do Índice de Relevância Jornalística (IRJ), o sistema possibilita quantificar os Indicadores de Relevância - os valores-notícia aplicados às matérias - mais usados pelos jornalistas de uma dada produção. Por exemplo, na Figura 7, pode-se verificar como os valores-notícia se distribuem entre as notícias. Na Categoria Atualidade, para a Matriz de Relevância considerada, há uma forte concentração nos valores-notícia "acompanhamento" e "factual". Já na categoria "Interesse Público", a ênfase é no valor-notícia 
"Poder Executivo". Tais quantitativos podem levar à proposição de metas (do tipo máxima e mínima ocorrência), e orientar o trabalho de seleção de pautas para aumentar ou diminuir a cobertura de determinados assuntos a depender da frequência ou da ausência de valores-notícia constatada.

Figura 7: Cópia de página* de consulta com quantitativo de valores-notícia acionados por matéria

\begin{tabular}{|c|c|}
\hline Valores-Notícia & $\mathrm{N}^{0}$ de Notícias \\
\hline & Matéria Info1 \\
\hline Categoria: Atualidade & 211 \\
\hline Subcategoria: Acompanhamento & 128 \\
\hline Subcategoria: Factual & 93 \\
\hline Subcategoria: Fria & 3 \\
\hline Subcategoria: Gancho & 8 \\
\hline Subcategoria: Novidade & 27 \\
\hline Subcategoria: Repercussão & 30 \\
\hline Subcategoria: Temática & 2 \\
\hline Categoria: Interesse público & 197 \\
\hline Subcategoria: Direitos Indivíduais & 14 \\
\hline Subcategoria: Direitos Políticos e Partidários & 7 \\
\hline Subcategoria: Direitos Sociais & 73 \\
\hline Subcategoria: Interesse coletivo & 26 \\
\hline Subcategoria: Interesse geral & 19 \\
\hline Subcategoria: Interesse individual & 3 \\
\hline Subcategoria: Ministério Público e Defensoria & 8 \\
\hline Subcategoria: Poder Executivo & 113 \\
\hline Subcategoria: Poder Judicário & 12 \\
\hline Subcategoria: Poder Lesgilativo & 19 \\
\hline Categoria: Potencial Impacto Público & 199 \\
\hline Subcategoria: Conflito & 103 \\
\hline Subcategoria: Decisão & 30 \\
\hline Subcategoria: Desdobramento & 42 \\
\hline Subcategoria: Mudança/Transformação & 24 \\
\hline Subcategoria: Preparação & 34 \\
\hline Subcategoria: Risco & 41 \\
\hline
\end{tabular}




\section{2 Índice de Pluralidade Jornalística (IPJ)}

Para avaliação do requisito pluralidade, são

identificados os pontos de vista (definidos no âmbito

da Matriz de Relatos) de acordo com o problema

ao qual a notícia se refere. 0 Índice de Pluralidade

Jornalística (IPJ) é definido pela divisão do número

de relatos do ponto de vista de menor ocorrência

pelo número de relatos do ponto de vista de maior

ocorrência, para cada problema avaliado.

Os dados a seguir extraídos aleatoriamente do

Qualijor mostram que, em um dado Problema (2),

derivado de um Macroproblema (1), houve seis

relatos (informação) de Crítica 1, 11 de Posição

1 e 14 de Posição 2. As posições 1 e 2 disputam

pretensões de interesse em relação ao problema

considerado. Para gerar o índice, divide-se a

menor ocorrência pela maior: 11/14. 0 resultado

é um IPJ de 0,78, situado em um grau de média pluralidade, considerado aceitável (significa

que, para cada dez relatos de Posição 2, foram

registrados cerca de $8[0,78]$ relatos de Posição

1). Mas os relatos de Crítica 1 são os que criticam

a Posição 1, portanto, são alinhados à Posição

2. Nesta circunstância, o IPJ resultante será

0,55 (11 [Posição 1] / 20 [Posição 2 + Crítica

1]), apresentando um grau de baixa pluralidade.

Através do sistema, é ainda possível identificar e

quantificar também quais fontes de informações

estão associadas a cada ponto de vista.

0s dados anteriormente citados são apenas

demonstrativos para explicar a dinâmica de

funcionamento do sistema. Em um ambiente de

produção, se os editores tivessem acesso a dados

deste tipo, em tempo real, poderiam reorientar a

cobertura, para ampliar a pluralidade de pontos

de vista no seu noticiário, dando mais voz a quem, até aquele momento, houvesse sido menos ouvido. 
Figura 8: Indicadores de Pontos de Vista para fins de extração do Índice de Pluralidade Jornalística (IPJ)

\begin{tabular}{|c|c|}
\hline RESUMO & \\
\hline Quantidade de matérias encontradas: & 13 \\
\hline Quantidade de informações encontradas: & 28 \\
\hline Período das Edições: & $04 / 07 / 2015$ à $06 / 08 / 2015$ \\
\hline
\end{tabular}

ITENS DE VERACIDADE: RELATO

Relato: Relato de Crítica 1

Matéria Informação

Relato: Relato de Posição 1 3

Relato: Relato de Posição 2 6

11

Relato: Relato de Posição 2

9

ITENS DE VERACIDADE: REPUTAÇÃO DA FONTE

Matéria Informação

Reputação da Fonte: Macro Problema 1

13

\section{3 Índice de Confiabilidade Jornalística (ICJ)}

Para a análise da confiabilidade, é aplicada a

Matriz de Relatos, que reúne diferentes tipos de relatos, organizados em duas grandes categorias: pontos de vista, os quais expressam uma perspectiva de fala; dados, que dão conta de elementos objetivos. 0 Índice de Confiabilidade Jornalística (ICJ) avalia três aspectos: 1) 0 grau de verificação que 0 relato permite, através da indicação das fontes; 2) 0 grau de demonstração da informação, aplicável a relato de dados, por meio da apresentação de provas; e 3) a distinção clara entre ponto de vista e relato de dados.
Através de uma escala de pontuação que varia de 0 (zero) a 1, com base em parâmetros definidos pela matriz, os relatos são pontuados no sistema. Quanto mais demonstrados e passíveis de verificação, isto é, permitirem a quem ler rastrear a informação dada para fins de comprovação, maior é a sua pontuação, podendo chegar a 1. Quanto mais claros estiverem os pontos de vista, identificados como tal e quem os emite, maior é a sua pontuação, também podendo chegar a 1 .

Na Figura 9, é possível verificar um print da tela de ranking da confiabilidade de notícias de uma determinada produção jornalística avaliada. 
Figura 9: Ranking de confiabilidade a partir da aplicação da Matriz de Confiabilidade

\begin{tabular}{|c|c|} 
Matérias(s): & 7 matérias(s) encontrada(s)! \\
\begin{tabular}{|clc} 
Posiçăo & Matéria & Pontuaçáo da Matéria \\
\hline 1 & Nenhum médico é uma ilha & 0,795454545454545 \\
2 & Um tratamento Injusto & 0,749761904761905 \\
3 & O remédio errado & 0,746954022988506 \\
4 & O que ele admira é a ditadura & 0,581423611111111 \\
5 & O governo na Emergência & 0,544464285714286
\end{tabular}
\end{tabular}

0 ICJ é um índice formal, avaliado a partir do próprio texto. Ele não produz a checagem da informação, mas avalia em que medida a notícia oferece ela mesma as possibilidades para que isso possa ser feito. Pode ser usado como um recurso inicial de checagem de matérias, através de um método amostral, provendo uma pré-seleção do material que poderia seguir para uma investigação de autenticidade.

\section{Conclusão}

0 artigo pretendeu apresentar o Qualijor, um sistema de gestão da produção jornalística orientado para a qualidade editorial, como produto de uma Pesquisa Aplicada e de Desenvolvimento Experimental. 0 sistema é inovador porque incorpora metodologias de avaliação de qualidade aplicáveis a produtos e processos jornalísticos. Para 0 seu desenvolvimento, dois foram os aspectos centrais enfrentados pela pesquisa.

0 primeiro, o de desenvolvimento do Qualijor em si. Para isso, foi necessário trazer a discussão sobre qualidade para a área de jornalismo, identificar requisitos a serem avaliados, indicadores para mensurar o grau de sucesso dos requisitos, modelar o sistema e fazer o seu desenvolvimento inicial (o trabalho em parceria com a equipe de engenharia da computação para gerar, passo a passo, todo o sistema). 0 resultado é um software pronto que tem sido usado para trabalhos experimentais de avaliação de qualidade. Testá-lo em um ambiente de produção é um desafio futuro. 0 s índices de qualidade extraídos através do sistema são importantes ferramentas de accountability e de transparência editorial.

0 segundo, foi a sistematização da metodologia de Pesquisa Aplicada e de Desenvolvimento Experimental, através da qual a elaboração conjunta da avaliação de qualidade e do software foi conduzida ao longo da investigação. Para dar conta dos vários aspectos teóricos, metodológicos e práticos envolvidos na empreitada, tornouse necessário sistematizar uma estrutura metodológica que garantisse a articulação das várias competências acionadas, tanto para a pesquisa quanto para a sua aplicação em um ambiente de produção jornalística. Os princípios 
Finalidade e Complementaridade tanto deixam claro o caráter aplicado da investigação, articulando recursos das Ciências Sociais Aplicadas e da área Tecnológica, demanda esta já sugerida por Meditsch (2004), Machado (2005) e Franciscato (2005), quanto superam a compartimentalização de saberes, isolados "em pacotes", como apontado por Zelizer (2010).

Ambas as questões apresentadas demonstraram, até 0 momento, consistência suficiente para 0 seu estágio atual de desenvolvimento, apesar das questões ainda em aberto ou não suficientemente amadurecidas. As metodologias embarcadas no software precisam ser ainda mais testadas, para demonstrar sua capacidade de distinguir bons e maus produtos jornalísticos. 0 Qualijor precisa ser melhorado em suas funcionalidades, para tornar-se mais amigável e prático. A metodologia de Pesquisa Aplicada e de Desenvolvimento Experimental também necessita ser colocada à prova em novas situações de investigação, a fim de se avaliar em que medida ela dá conta dos desafios a que se propõe. Todas essas questões apontam, contudo, para passos futuros no sentido de avançar sobre 0 que temos desenvolvido até 0 momento.

\section{Referências}

ABNT NBR ISO 9000:2005. Sistemas de Gestão da Qualidade - Fundamentos e vocabulário.

ALMEIDA, Mário de Souza, FREITAS, Cláudia Regina, SOUSA, Irineu Manoel de. Gestão do conhecimento para a tomada de decisão. São Paulo: Atlas, 2011. 114 p.
ANDERSON C.W., BELL, Emily, SHIRKY, Clay. PostIndustrial Journalism: Adapting to the present. Columbia Journalism School, Tow Center for Digital Journalism, 2012. Disponível em < http://towcenter. org/wp-content/uploads/2012/11/TOWCenter-Post_ Industrial_Journalism.pdf > BARB0ZA, Suzana Oliveira. Jornalismo Digital em Ambientes Dinâmicos. Propriedades, rupturas e potencialidades do Modelo JDBD. Observatório (OBS*) Journal, 4 (2008), 217-244. Disponível em: file:///C:/Users/ jl_gu_000/Dropbox/Disciplinas/0n\%20Line\%20II\%20 2016/136-775-1-PB(1).pdf. Data de acesso: 30/06/2016.

BENEDETI, Carina Andrade. A Qualidade da Informação Jornalística: Do conceito à prática. FIorianópolis/SC: Insular, 2009. Série Jornalismo a Rigor, Volume 2.

BERTRAND, Claude-Jean. 0 arsenal da democracia: sistemas de responsabilização da mídia. Tradução de Maria Leonor Loureiro. Bauru, SP: Edusc, 2002. 513 p.

BRITO, Judith. Mudam os paradigmas, não 0 jornalismo. Jornal da ANJ, abril de 2011. Disponível em: < http://www.anj.org.br/sala-de-imprensa/artigos/ mudam-os-paradigmas-nao-0-jornalismo/ > . Acessado em 28 de abril de 2013.

CERQUEIRA, Luiz Augusto Egypto de. Qualidade jornalística: ensaio para uma matriz de indicadores. Brasília: UNESCO, 2010. (Série Debates CI: Comunicação e Informação; 6).

CHRISTIANS, Clifford G., GLASSER, Theodore, MCQUAIL, Dennis, NORDENSTRENG, Kaarle, WHITE, Robert A. Normative Theories of the Media. Journalism and Democratic Societies. Urbana and Chicago: University of Illinois Press, 2009. 280 p.

CHRISTOFOLETTI, Rogério. "Indicadores da Qualidade no Jornalismo: políticas, padrões e preocupações de jornais e revistas brasileiros". Brasília: UNESCO, 2010. (Série Debates CI: Comunicação e Informação; 3). 
CORNU, Daniel. Ética da

informação. Bauru: Edusc, 1998.

FAÇANHA, Sandra L. e YU, Abraham Sin Oih.

"Abordagem integrada". In: YU, Abraham Sin Oih.

(Org.). Tomada de decisão nas organizações: uma

visão multidisciplinar. São Paulo: Saraiva, 2011. p.

51-78.

FEITOZA, Liliane do N. S. Relevância jornalística: análise e teste de ferramenta para fins de avaliação de qualidade e accountability. São Cristóvão, UFS, 2016. 200 f.

Dissertação (mestrado em Comunicação) - Programa de Pós-Graduação em Comunicação, Universidade Federal de Sergipe (UFS), São Cristóvão, 2016.

FENGLER, Susanne, EBERWEIN, Tobias, MAZZOLENI, Gianpietro, PORLEZZA, Colin, RUSS-MOHL, Stephan. (org.). Journalists and Media Accountability: An International Study of News People in the Digital Age. New York: Peter Lang, 2014

FONSECA, Virginia P. da S., SEIBT, Taís. "A

Contribuição de Max Weber para os Estudos do Jornalismo: um ensaio teórico-Metodológico". Intexto, Porto Alegre, UFRGS, n. 34, p. 640-657, set./dez. 2015. D0I:http://dx.doi.org/10.19132/1807-8583201534.640657.Data de acesso: 13/06/2016.

FONSECA, Virgínia P. da S. Jornalismo, ação racional conforme os fins e os valores. Revista da Associação Nacional dos Programas de Pós-Graduação em Comunicação | E-compós, Brasília, v.19, nº1, jan/abr. 2016. Disponível em: http://www.compos.org.br/seer/ index.php/e-compos/article/view/1149/873. Data de acesso: 28/06/2016.

FRANCISCATO, 2006. Considerações metodológicas sobre a pesquisa aplicada em jornalismo. Brasília, SBPJor, 2006. Anais, $4^{0}$ Congresso Brasileiro de Pesquisadores em Jornalismo (SBPJor).

GENTILLI, Victor. Democracia de massas:

jornalismo e cidadania. Porto Alegre, Editora da PUCRS, 2005.
GOMES, Wilson. Transformações da política na era

da comunicação. São Paulo: Paulus, 2004.

GUERRA, Josenildo Luiz. 0 percurso interpretativo na produção da notícia. São Cristóvão: Editora UFS; Aracaju: Fundação Oviêdo Teixeira, 2008. "Sistema de Gestão de Qualidade aplicado ao Jornalismo: possibilidades e diretrizes". In: Revista da Associação Nacional dos Programas de Pós-Graduação em Comunicação | E-compós, Brasília, v.13, nº 3, set./dez. 2010b.

GUERRA, Josenildo Luiz, BARRETO, Nara. Qualidade em Jornalismo: metodologia para avaliação do requisito relevância. Brasília, SBPJor, 2013. Anais, $11^{\circ}$ Congresso Brasileiro de Pesquisadores em Jornalismo (SBPJor).

GUERRA, Josenildo Luiz, LINS, Alanna M. V. Índice de Pluralidade Jornalística (IPJ): testando uma metodologia para avaliação de qualidade editorial. Brasília, SBPJor, 2014. Anais, $12^{\circ}$ Congresso Brasileiro de Pesquisadores em Jornalismo (SBPJor).

JORNET, Carlos. Gestión periodistica. Herramientas para lograr un periodismo efectivo y de calidad. 1 ed. Buenos Aires: Prometeo Libros, 2006.

MACHAD0, Elias. Dos Estudos sobre o Jornalismo às teorias do Jornalismo (Três Pressupostos para a Consolidação do Jornalismo como Campo de Conhecimento). E-compós - Revista de Associação Nacional dos Programas de Pós-Graduação em Comunicação. Ed.1, dez 2004. Disponível na Internet: http://www.compos.org.br/e-compos. Data de acesso: 13/06/2016.

0 Jornalismo Digital em Base

de Dados. Florianópolis: Calandra, 2006. 148 p.

MANUAL DE FRASCATI. Medição de atividades científicas e tecnológicas: Tipo de metodologia proposta para levantamentos sobre pesquisa e desenvolvimento experimental. OCDE, 2002. Disponível em http://www. mct.gov.br/upd_blob/0225/225728.pdf 
McQUAIL, Denis. Media Accountability and Freedom of Publication. Oxford; New York: Oxford University Press, 2003.

\section{MARINHO, Sandra. Jornalismo e formação em} mudanças: modelos e construções na análise do caso português. Braga, Portugal: CECS - Centro de Estudos de Comunicação e Sociedade Universidade do Minho, 2015. 559 p.

MEDITSCH. Eduardo. Estudos em Jornalismo. Revista Brasileira de Ciências da Comunicação. Vol XXVII, $n^{\circ}$ 2, jul/dez 2004. São Paulo: INTERCOM, 2004, p. 93-107. Disponível em: http://www.portcom.intercom.org. br/revistas/index.php/revistaintercom/article/ viewFile/1070/971. Data de acesso: 13/06/2016.

MEYER, Phipip. Os jornais podem desaparecer? Como salvar o jornalismo na era da informação. São Paulo: Contexto, 2007.

MONPART, Josep L. Gómez, LOZANO, Juan F. Gutiérrez, SAMPI0, Dolors Palau (Org.). La calidad periodística: teorias, investigaciones y sugerencias profesionales. Barcelona: Universitat Autònoma de Barcelona/Universitat Pompeu Fabra, D.L. 2013.

NORRIS, Pippa, ODUGBEMI, Sina. "The Roles of the News Media in the Governance Agenda: Watch-dogs, AgendaSetters, and Gate-Keepers". In.: Harvard University-World Bank workshop on "The Role of the News Media in the Governance Agenda: Watc-Jdog, Agenda-setter, and Gatekeeper." 29-31 $1^{\text {st }}$ May 2008. Disponível em http://issuu.com/ internews/docs/mediamatters?mode=embed\&document $\mathrm{Id}=080307235258-86879280152 \mathrm{~d} 4 \mathrm{~cd} 485010 \mathrm{c} 7 \mathrm{~d} 3 \mathrm{a} 09 \mathrm{c} 955$ \&layout=grey Acesso em 25 mar 2009.

O'BRIEN, James A. Sistemas de Informação e as decisões gerenciais na era da internet. $3^{\mathrm{a}} \mathrm{ed}$. Tradução de Célio Knipel Moreira e Cid Knipel Moreira. Rev. Téc. de Luiz Eduardo de Abreu da Cunha. São Paulo: Saraiva, 2010. 431 p.

ROTHBERG, Danilo. "Jornalistas e suas visões sobre qualidade: teoria e pesquisa no contexto dos
'Indicadores para o Desenvolvimento da Mídia' da UNESCO". UNESC0, 2010. (Série Debates CI: Comunicação e Informação; 5 .

SLACK, Nigel, STUART, Chambers, JOHNSTON, Robert. Administração da produção. Tradução de Maria Teresa Corrêa de Oliveira e Fábio Alher. Revisão Técnica de Henrique Luiz Corrêa. São Paulo: Atlas, 2007.

STAL, Eva. "Inovação tecnológica, sistemas nacionais de inovação e estímulos governamentais à inovação". In.: MOREIRA, Daniel Augusto e QUEIR0Z, Ana Carolina (org.). Inovação organizacional e tecnológica. São Paulo: Thomson Learning, 2007.(p. 23-53)

SUÁREZ, Adriana Amado. Periodismo de calidad: debates y desafios. Buenos Aires: La Crujía: FOPEA, 2007.

TAVARES, Bruno da S. Pluralidade na cobertura do Jornal Nacional sobre os preparativos para Copa do Mundo 2014: Avaliação da conformidade do conteúdo jornalístico com as garantias do documento editorial da Globo. São Cristóvão, UFS, 2014. 142 f. Dissertação (mestrado em Comunicação) - Programa de Pós-Graduação em Comunicação, Universidade Federal de Sergipe (UFS), São Cristóvão, 2014.

TORRES JUNIOR, Alvair Silveira, MOURA, Gilnei. Decisão em administração - uma discussão. In: YU, Abraham Sin Oih. (Org.). Tomada de decisão nas organizações: uma visão multidisciplinar. São Paulo: Saraiva, 2011. p. 3-22.

ZELIZER, Barbie. Going beyond Disciplinary Boundaries in the Future of Journalism Research. In.: LÖFFELHOLZ, Martin, WEAVER, David. Global Journalism Research. Theories, Methods, Findings, Future. Malden, MA, USA; Oxford, UK: Blackwell Publishing, 2008. (p. 253-266) 
Qualijor - Management System

of Journalistic Production oriented

for editorial quality: Applied

Research and Experimental

Development in Journalism

\section{Abstract}

This paper presents the Qualijor, a management system of journalistic production oriented for the editorial quality that generates performance indicators for managers and their teams. Qualijor was born from theoretical concerns coupled with the intention of Applied Research and Experimental Development (R \& D) to both measure the quality of journalism and to drive innovation in the production process in order to improve their results. The efforts made aimed the following results: 1) suggesting a management model of journalistic production based on indicators for evaluating editorial quality; 2) systematizing a methodology propose of Applied Research and Experimental Development in journalism.

\section{Keywords}

Journalism; Quality; Applied Research
Qualijor - Sistema de Gestión de la Producción Periodística orientado a la calidad editorial: Investigacción Aplicada y de Desarrollo Experimental en Periodismo

\section{Resumen}

El artículo propone el Qualijor, un sistema de gestión de la producción periodística orientado a la calidad editorial, que genera indicadores de rendimiento hacia los gestores y sus equipos. El Qualijor surgió a partir de preocupaciones teóricas con la intención de Investigación Aplicada y de Desarrollo Experimental (I + D) tanto para medir la calidad de la actividad periodística cuanto para generar innovación en lo proceso productivo, con el fin de mejorar sus resultados. Los esfuerzos realizados intentaran los siguientes resultados: 1) sugerir un modelo de gestión de la producción periodística con base en indicadores de calidad editorial; 2) sistematizar una propuesta metodológica de Investigación Aplicada y de Desarrollo Experimental en Periodismo.

\section{Palabras clave}

Periodismo; Calidad; Investigación Aplicada 


\section{Expediente}

A revista E-Compós é a publicação científica em formato eletrônico da Associação Nacional dos Programas de Pós-Graduação em Comunicação (Compós). Lançada em 2004, tem como principal finalidade difundir a produção acadêmica de pesquisadores da área de Comunicação, inseridos em instituições do Brasil e do exterior.

\section{E-COMPÓS I www.e-compos.org.br I E-ISSN 1808-2599}

Revista da Associação Nacional dos Programas de Pós-Graduação em Comunicação.

Brasília, v.19, n.3, set./dez. 2016.

A identificação das edições, a partir de 2008, passa a ser volume anual com três números.

Indexada por Latindex I www.latindex.unam.mx

\section{CONSELHO EDITORIAL}

Alexandre Farbiarz, Universidade Federal Fluminense, Brasil Alexandre Rocha da Silva, Universidade Federal do Rio Grande do Sul, Brasil Ana Carolina Escosteguy, Pontifícia Universidade Católica do Rio Grande do Sul, Brasil Ana Carolina Rocha Pessôa Temer, Universidade Federal de Goiás, Brasil Ana Regina Barros Rego Leal, Universidade Federal do Piauí, Brasil Andrea França, Pontifícia Universidade Católica do Rio de Janeiro, Brasil André Luiz Martins Lemos, Universidade Federal da Bahia, Brasil Antonio Carlos Hohlfeldt, Pontifícia Universidade Católica do Rio Grande do Sul, Brasil Arthur Ituassu, Pontifícia Universidade Católica do Rio de Janeiro, Brasil Álvaro Larangeira, Universidade Tuiuti do Paraná, Brasil Ângela Freire Prysthon, Universidade Federal de Pernambuco, Brasil César Geraldo Guimarães, Universidade Federal de Minas Gerais, Brasil Cláudio Novaes Pinto Coelho, Faculdade Cásper Líbero, Brasil Daisi Irmgard Vogel, Universidade Federal de Santa Catarina, Brasil Denize Correa Araujo, Universidade Tuiuti do Paraná, Brasil

Eduardo Antonio de Jesus, Pontifícia Universidade Católica de Minas Gerais, Brasil Daniela Zanetti, Universidade Federal do Espirito Santo, Brasil

Eduardo Vicente, Universidade de São Paulo, Brasil

Elizabeth Moraes Gonçalves, Universidade Metodista de São Paulo, Brasil Erick Felinto de Oliveira, Universidade do Estado do Rio de Janeiro, Brasil Francisco Elinaldo Teixeira, Universidade Estadual de Campinas, Brasil Francisco Paulo Jamil Almeida Marques, Universidade Federal do Paraná, Brasil Gabriela Reinaldo, Universidade Federal do Ceará, Brasil

Goiamérico Felício Carneiro Santos, Universidade Federal de Goiás, Brasil Gustavo Daudt Fischer, Universidade do Vale do Rio dos Sinos, Brasil Herom Vargas, Universidade Municipal de São Caetano do Sul, Brasil Itania Maria Mota Gomes, Universidade Federal da Bahia, Brasil Janice Caiafa, Universidade Federal do Rio de Janeiro, Brasil Jiani Adriana Bonin, Universidade do Vale do Rio dos Sinos, Brasil
José Afonso da Silva Junior, Universidade Federal de Pernambuco, Brasil José Luiz Aidar Prado, Pontifícia Universidade Católica de São Paulo, Brasil Juçara Gorski Brittes, Universidade Federal de Ouro Preto, Brasil Kati Caetano, Universidade Tuiuti do Paraná, Brasil Lilian Cristina Monteiro França, Universidade Federal de Sergipe, Brasil Liziane Soares Guazina, Universidade de Brasilia, Brasil Luíza Mônica Assis da Silva, Universidade de Caxias do Sul, Brasil Luciana Miranda Costa, Universidade Federal do Pará, Brasil Malena Segura Contrera, Universidade Paulista, Brasil Monica Martinez, Universidade de Sorocaba, Brasi Maria Ataide Malcher, Universidade Federal do Pará, Brasil Marcia Tondato, Escola Superior de Propaganda e Marketing, Brasil Marcel Vieira Barreto Silva, Universidade Federal da Paraíba, Brasil Maria Clotilde Perez Rodrigues, Universidade de São Paulo, Brasil Maria das Graças Pinto Coelho, Universidade Federal do Rio Grande do Norte, Brasil Mauricio Ribeiro da Silva, Universidade Paulista, Brasil

Mauro de Souza Ventura, Universidade Estadual Paulista, Brasil Márcio Souza Gonçalves, Universidade do Estado do Rio de Janeiro, Brasil Micael Maiolino Herschmann, Universidade Federal do Rio de Janeiro, Brasil Mirna Feitoza Pereira, Universidade Federal do Amazonas, Brasil Nísia Martins Rosario, Universidade Federal do Rio Grande do Sul, Brasil Potiguara Mendes Silveira Jr, Universidade Federal de Juiz de Fora, Brasil Regiane Regina Ribeiro, Universidade Federal do Paraná, Brasil Rogério Ferraraz, Universidade Anhembi Morumbi, Brasil Rose Melo Rocha, Escola Superior de Propaganda e Marketing, Brasil Rozinaldo Antonio Miani, Universidade Estadual de Londrina, Brasil Sérgio Luiz Gadini, Universidade Estadual de Ponta Grossa, Brasil Simone Maria Andrade Pereira de Sá, Universidade Federal Fluminense, Brasil Veneza Mayora Ronsini, Universidade Federal de Santa Maria, Brasil Walmir Albuquerque Barbosa, Universidade Federal do Amazonas, Brasil

\section{CONSELHO CIENTÍFICO}

Cristiane Freitas Guttreind, Pontifícia Universidade Católica do Rio Grande do Sul, Brasil Eduardo Morettin, Universidade de São Paulo, Brasil Felipe Costa Trotta, Universidade Federal Fluminense, Brasil Irene de Araújo Machado, Universidade de São Paulo, Brasil

\section{COMISSÃO EDITORIAL}

Eduardo Antonio de Jesus, Pontifícia Universidade Católica de Minas Gerais, Brasil Osmar Gonçalves dos Reis Filho, Universidade Federal do Ceará, Brasil

\section{CONSULTORES AD HOC}

Geane C. Alzamora, Universidade Federal de Minas Gerais, Brasil Teresinha Cruz Pires, Pontifícia Universidade Católica de Minas Gerais, Brasil

\section{EQUIPE TÉCNICA}

ASSISTENTE EDITORIAL Márcio Zanetti Negrini

REVISÃO DE TEXTOS Press Revisão

EDITORAÇÃO ELETRÔNICA Roka Estúdio

IMAGEM DE CAPA Silas de Paula

\section{COMPÓS I www.compos.org.br}

Associação Nacional dos Programas de Pós-Graduação em Comunicação

Presidente

Edson Fernando Dalmonte

Programa de Pós-Graduação em Comunicação

e Cultura Contemporânea - UFBA

edsondalmonte@uol.com.br

Vice-presidente

Cristiane Freitas Gutfreind

Programa de Pós-Graduação em Comunicação Social - PUC-RS cristianefreitas@pucrs.br

Secretário-Geral

Rogério Ferraraz

Programa de Pós-Graduação em Comunicação

Universidade Anhembi Morumbi

rogerioferraraz@anhembimorumbi.edu.br

CONTATO I revistaecompos@gmail.com 